\title{
Regional Properties of Calcium Entry in Barnacle Neurons Determined with Arsenazo III and a Photodiode Array
}

\author{
William N. Ross, Lisa Lewenstein Stockbridge, ${ }^{1}$ and Norman L. Stockbridge ${ }^{2}$ \\ Department of Physiology, New York Medical College, Valhalla, New York 10595, and \\ The Marine Biological Laboratory, Woods Hole, Massachusetts 02543
}

Calcium changes were simultaneously measured at many positions on individual neurons from the supraesophageal ganglion of the barnacle by detecting absorbance changes of the indicator dye Arsenazo III with a $10 \times 10$ photodiode array. These changes were correlated with positions on the stimulated cell determined from Lucifer yellow injections. Absorbance signals were found at all locations on the cells, demonstrating that calcium channels were distributed on the somata, axons, and neuropil processes. By comparing the amplitude of the signal with the membrane area in each region, we could measure the calcium entry per impulse per unit of surface in each part of the cell. Assuming that the properties of the calcium channels are the same in all regions, we determined that calcium channels were distributed uniformly along the commissural axon of one cell and were found at higher density in the neuropil.

Because significant calcium changes are only detected when cells are depolarized above about $-\mathbf{2 0} \mathbf{m V}$, the presence of absorbance signals indicates membrane depolarization above this level. We used this fact to show that calcium spikes propagate along the axon and into the neuropil of one cell, along the axon of another, and not at all in a third.

Differences in time course of calcium transients were observed in different regions of cells. The recovery time course was faster at the edge of the cell body than in the center and faster in the neuropil than in the axon or soma. During trains of action potentials or during wide action potentials in tetraethylammonium (TEA) saline, the calcium signal reached a plateau in the neuropil while continuing to rise in the axon and soma.

Calcium plays a variety of roles within neurons, including control of transmitter release (Katz, 1969), alteration of enzyme action (Rasmussen, 1981), modulation of specific conductances (Meech, 1978), as well as being a current carrier through specific ion channels (Hagiwara, 1973). These effects are often thought to be segregated in particular regions of the cell, contributing to the specialization of different parts of the neuron (Llinas and Sugimori, 1979). There is evidence that some of the main regulators of internal calcium concentration (calcium channels and

Received June 10, 1985; revised Oct. 4, 1985; accepted Oct. 9, 1985.

This work was supported in part by United States Public Health Service Research Grant NS-016295 (W.N.R.), National Research Scientist Award Fellowship NS-07172 (N.L.S.), and an Irma T. Hirschl Career Scientist Award (W.N.R.). We would like to thank Nechama Lasser-Ross for most of the computer programming, Amiram Grinvald for help with the electronics, and Larry Cohen, Victor Krauthamer, Jill London, Henry Matzner, Bob Werman, and Dan Zecevic for comments on the manuscript.

Comrespondence should be addressed to Dr. W. N. Ross, Department of Physiology, New York Medical College, Valhalla, NY 10595.

1 Present address: Department of Physiology, University of Alberta, Edmonton, Canada T6G 2G3.

${ }^{2}$ Present address: Division of Neurosurgery, University of Alberta, Edmonton, Canada T6G 2G3.

Copyright @ 1986 Society for Neuroscience $0270-6474 / 86 / 041148-12 \$ 02.00 / 0$ intracellular buffers) are unevenly distributed. For example, Katz and Miledi (1969) showed that calcium channels are concentrated in the presynaptic terminal region of the squid giant synapse and Tillotson and Gorman (1980) showed that in the cell $\mathrm{R} 15$ of Aplysia buffering is stronger at the edge than at the center of the neuron (see also Mullins and Requena, 1979). However, these regional variations have not been extensively analyzed because calcium changes in cells have almost always been measured with single electrodes or single optical detectors, which only report changes at one position at a time.

Calcium changes in cells can be measured using either ionselective electrodes or optical detection of changes in absorption, fluorescence, or luminescence of appropriate indicators (reviewed in Blinks et al., 1982). One of the advantages of using optical methods is that this technique can be extended in a straightforward way to detect changes simultaneously at many positions. Jaffe and his colleagues (Gilkey et al., 1978) first used this approach to look at the wave of calcium entry in fertilized medaka eggs. They injected eggs with the calcium-sensitive photoprotein aequorin and detected the spread of luminescence with an image intensifier and vidicon camera. Using a similar apparatus, Llinás et al. (1983) have looked at calcium entry in the presynaptic terminal of the squid giant synapse. Recently, Harary and Brown (1984) used a linear array of detectors and the dye Arsenazo III to look at calcium in the Limulus ventral photoreceptor.

To explore the regional properties of calcium entry in neurons, we have measured changes in absorption of the metallochromic indicator Arsenazo III (Brown et al., 1975; DiPolo et al., 1976) simultaneously at many positions with a $10 \times 10$ array of photodiodes (Grinvald et al., 1981a; Ross and Krauthamer, 1984). By correlating these signals with positions on the cell as determined from Lucifer yellow injections, we could assign simultaneously measured absorption changes to the soma, dendrites, axons, and presynaptic terminals of various neurons. Since these absorption changes are proportional to the changes in calcium and have a rapid response time (reviewed in Blinks et al., 1982; and see Materials and Methods, below), we could make quantitative comparisons of the amplitudes and time courses of the calcium transients in the different regions. We first used this method to demonstrate that calcium channels were concentrated in the presynaptic terminals of a barnacle photoreceptor (Stockbridge and Ross, 1984). In this paper, we show that the neuropil region of some ganglionic neurons also has a relatively high concentration of calcium channels and that the time course of the calcium transients evoked by stimulating the cell differs in this region from those of the axon and soma. In addition, we demonstrate how the simultaneous measurement of calcium signals in different regions can be used to examine the propagation of electrical signals within neurons.

Preliminary versions of this work have been published in 
abstract form (Lewenstein and Ross, 1984b; Lewenstein et al., 1984; Ross et al., 1984).

\section{Materials and Methods}

Large barnacles, Balanus nubilus, were obtained from Puget Sound, Washington, and kept in either recirculated or flowing sea water at 8$12^{\circ} \mathrm{C}$. The supraesophageal ganglion was dissected out as previously described (Hudspeth and Stuart, 1977) and mounted in a plastic chamber coatcd with Sylgard (Dow Corning), using strips of Teflon tape to hold the ganglion immobile (Ross and Krauthamer, 1984). Most experiments were done on three different neurons of the ganglion: (1) "marginal cells" (MG) (Ross and Krauthamer, 1984), found along the anteromedial border of each hemiganglion with an axon projecting out the ipsilateral antennular nerve and a neuropil arborization in the same hemiganglion; (2) "cross-commissural" (CC) cells (Lewenstein, 1983), one in each hemiganglion with a soma on the posteromedial border, projecting an axon across the commissure and out the contralateral antennular nerve. These cells have a wide arborization in the ipsilateral hemiganglion and a smaller arborization in the contralateral hemiganglion; (3) "medial-commissural" (MC) cells, one in each hemiganglion with a large soma close to the commissure, with an axon that crosses the commissure to an arborization adjacent to the commissure in the contralateral hemiganglion. These cells are illustrated in Figure 1.

The chamber was mounted on the stage of a Zeiss Universal microscope. Microelectrodes and suction electrodes were controlled with hydraulic manipulators (Narashige, M-103) mounted on the stage to permit changing the field of view while maintaining the electrodes in position (Grinvald et al., 1981b; Ross and Krauthamer, 1984).

For direct electrical recording, electrodes were filled with $3 \mathrm{~m} \mathrm{KCl}$. For iontophoresis of Arsenazo III, the tips of the electrodes were filled with $75 \mathrm{~mm}$ dye (Sigma, 8992) and backfilled with $3 \mathrm{M} \mathrm{KCl}$. For iontophoresis of Lucifer yellow, the tips were filled with $0.05 \mathrm{M}$ dye (Aldrich Chemical Co.) and backfilled with $1 \mathrm{~m} \mathrm{LiCl}$. Both dyes were used without purification and were maintained in stock solutions at the indicated concentrations. Normal saline was $\mathrm{NaCl}, 461.5 \mathrm{~mm} ; \mathrm{KCl}, 8$ $\mathrm{mm} ; \mathrm{CaCl}_{2}, 20 \mathrm{~mm} ; \mathrm{MgCl}_{2}, 12 \mathrm{~mm}$, and HEPES buffer, $5 \mathrm{~mm}$ (pH 7.6). When used, tetraethylammonium (TEA) chloride was substituted 1:1 for $\mathrm{NaCl} . \mathrm{CoCl}_{2}$ was substituted for $\mathrm{CaCl}_{2}$ or added to the saline. TTX was maintained in a stock solution of $10^{-5} \mathrm{gm} / \mathrm{ml}$ and diluted 1:100 with saline to give a final concentration of $3 \times 10^{-7} \mathrm{M}$. Experiments were done at room temperature, $18-22^{\circ} \mathrm{C}$.

After impaling a cell, Arsenazo III was iontophoresed using $500 \mathrm{msec}$ hyperpolarizing pulses of $1-3 \mathrm{nA}$ and a duty cycle of $50 \%$. For most cells, dye was injected until the soma was just pink, at which point the concentration there was about $0.3-0.4 \mathrm{~mm}$. Dye concentration in the soma $(C)$ was estimated by measuring the transmission change in the center of the cell at $580 \mathrm{~nm}$, which is close to the isosbestic point of the dye. Beer's law $\left(I=I_{0} \times 10^{-\leftarrow L C}\right)$ with a molar absorption coefficient of $\epsilon=3 \times 10^{4} \mathrm{M}^{-1} \mathrm{~cm}^{-1}$ (Ahmed et al., 1980) was used. In calculating the path length $(L)$, the soma was assumed to be spherical. No attempt was made to correct this measurement for light scattering (Charlton et al., 1982). After injection, the dye was allowed to diffuse about $30 \mathrm{~min}$. For some cells this was not long enough for the dye to reach equilibrium since repeated experiments gave signals over wider areas of dendritic arborization. However, the dye eventually diffused over the full dendritic field of the cells and at least $2000 \mu \mathrm{m}$ along the axon with no indication of any diffusion barrier. Experiments such as those shown in Figure 12 indicate that an equilibrium distribution was reached in less than $1 \mathrm{hr}$, since significant changes in signal size and shape were not observed at longer times. Stable recordings and signals were often obtained for 3-5 hr after the beginning of an experiment.

For the optical experiments, the ganglion was illuminated with a 12 $\mathrm{V}, 100 \mathrm{~W}$ tungsten-halogen lamp controlled with a stabilized DC power supply (Kepco, JQE-25M). The condenser had a numerical aperture of 0.9 and was adjusted for Kohler illumination. The wavelength of illumination was selected with interference filters. Filters used to determine the action spectrum had a nominal width of $10 \mathrm{~nm}$. Calcium signals were first detected with a $660 \pm 15 \mathrm{~nm}$ filter (Baylor et al., 1982b). After controls established that our signals came from calcium entry and were not significantly contaminated with signals from changes in $\mathrm{pH}$ or magnesium concentration, and that signals measured between 620 and $660 \mathrm{~nm}$ had a similar time course (see below), we used a $640 \pm 30 \mathrm{~nm}$ filter to obtain larger signals.

The ganglion was imaged onto the $10 \times 10$ photodiode array using either of two water-immersion lenses-a $25 \times$, NA 0.60 (Leitz, 619706)

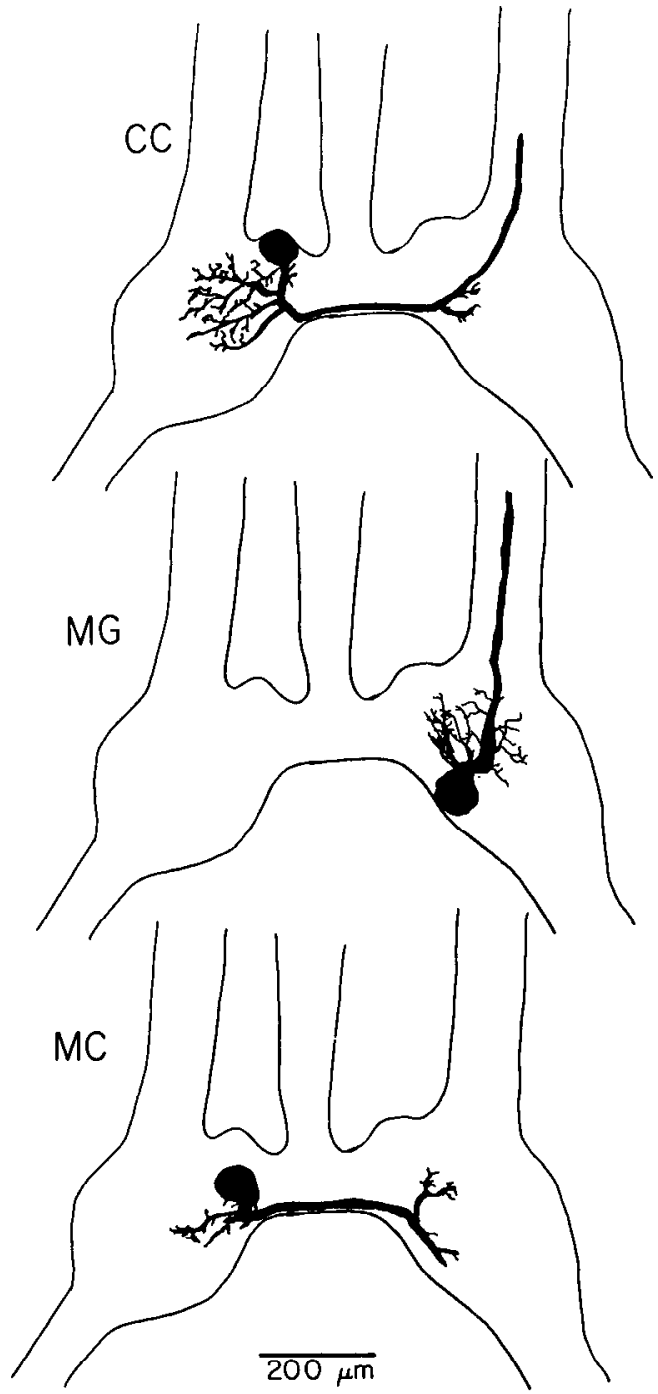

Figure 1. Drawings of $C C, M C$, and $M G$ cells superimposed on outlines of the barnacle supraesophageal ganglion. The nerves at the bottom are the circumesophageal connectives; above, the two antennular nerves and the medial nerve. Cell shapes were determined from Lucifer yellow fills of these neurons. A photograph of the live ganglion appears in Figure 1 of Ross and Krauthamer (1984).

or a $40 \times$, NA 0.75 (Zeiss, 5232814). In conjunction with the Optovar of the microscope, these lenses allowed each photodiode element to record from areas of different sizes ranging from $25 \times 25$ to $64 \times 64$ $\mu \mathrm{m}^{2}$ in the plane of the ganglion.

The current outputs of the 96 photodiode elements (the four corner elements were unused) were converted to voltage with operational amplifiers and RC-filtered with a low-pass time constant of $10 \mathrm{msec}$. In order to increase the resolution of the measurement, the steady-state intensity level on each channel was subtracted using a sample-and-hold circuit and difference amplifier (Baylor et al., 1982a; Grinvald et al. 1982; Nakajima et al., 1976) and the resulting signal was further amplified $2000 \times$. These signals were sampled and digitized with 12 bit accuracy using two separate analog-to-digital convertors (ADAC, 1023 and Data Translation, 3382). These convertors could store data in parallel under direct memory access (DMA) with a combined rate of 300 $\mathrm{kHz}$, allowing a complete polling of all 96 channels in $0.333 \mathrm{msec}$. During the early stages of our work, many experiments were performed using only the central 32 elements of the array and the ADAC convertor. For the experiments described in this paper, the channels were sampled at a rate between 30 and $100 \mathrm{~Hz}$. Corrections for the small drift in the sample-and-hold circuit were made during data acquisition by subtracting a reference trace from each stimulated record. The data were analyzed and displayed using an LSI-11/23 minicomputer. 


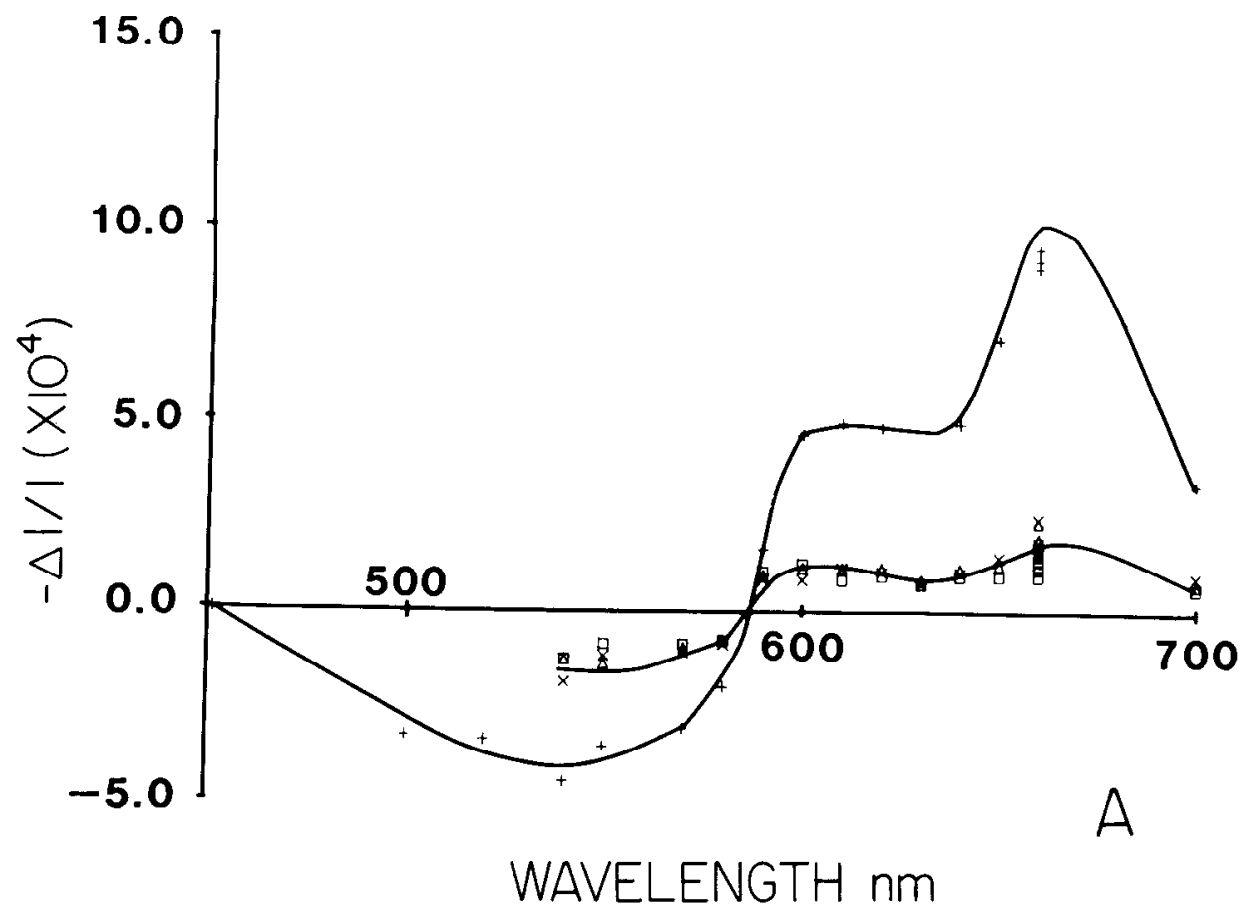

Figure 2. A, Action spectrum of the dye Arsenazo III in different regions of the $\mathrm{CC}$ cell. For each wavelength the amplitude of the absorbance change during a standard stimulation was divided by the resting intensity at that wavelength. Recordings were made from the soma $(+)$, from positions over the ipsilateral neuropil $(\square, \Delta)$, and from over the axon $(x)$. The soma point at $660 \mathrm{~nm}$ was measured several times during the experiment and the scatter indicates the drift and/or error in our measurements. The curves were fitted by eye. $B$, Difference in recovery time course in the soma, measured at different wavelengths after a standard stimulating pulse. The signals haave been normalized to the same amplitude. The early part of the time course at $600 \mathrm{~nm}$ is faster than at the other indicated wavelengths.

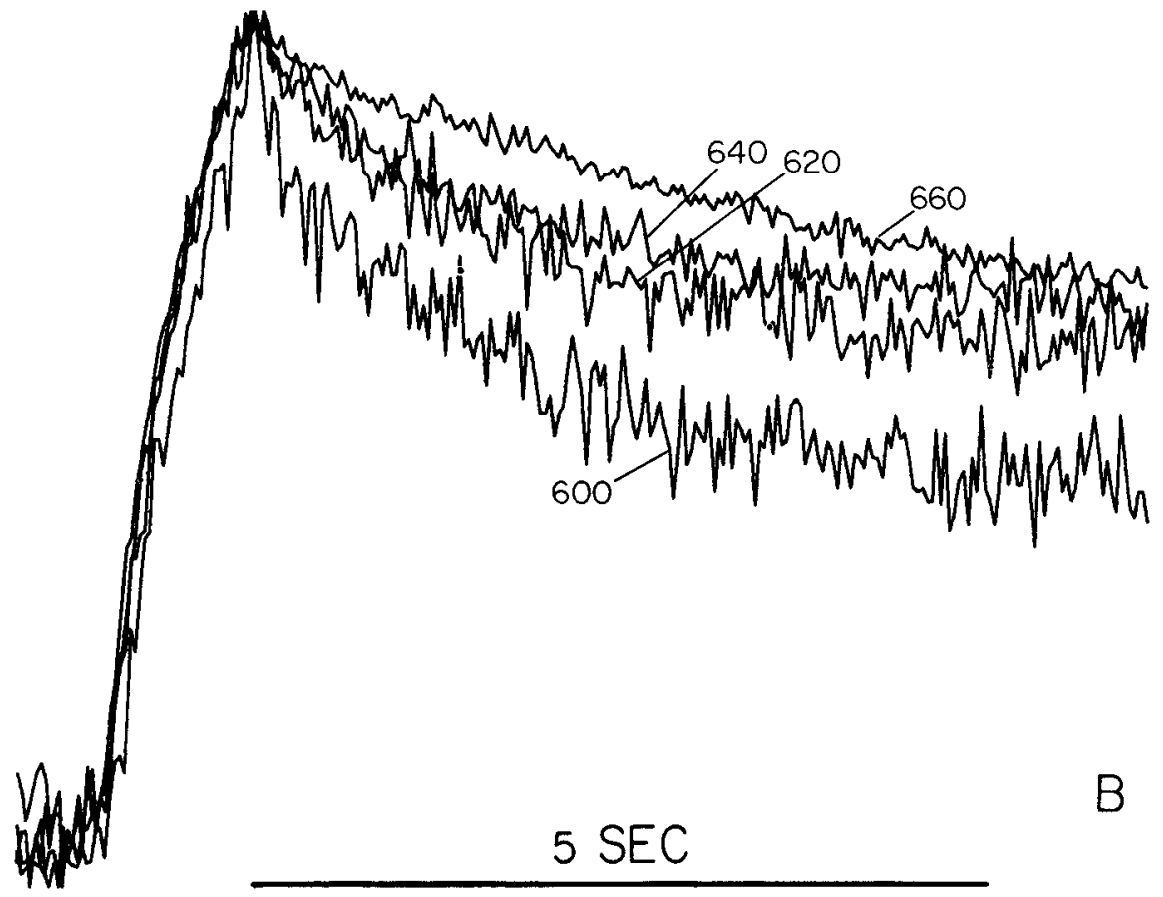

With this apparatus, we were able to resolve absorbance changes of $2 \times 10^{-5}$ in a single sweep using the $25 \times$ lens and the $640 \pm 30 \mathrm{~nm}$ filter. If a 5- $\mu \mathrm{m}$-diameter axon passes through the field of one diode element $\left(64 \mu \mathrm{m}^{2}\right)$ and is filled with $0.25 \mathrm{~mm}$ dye, then this sensitivity implies that we could detect a concentration change of about $2 \mu \mathrm{M}$ in a single sweep (using the calibration of Gorman and Thomas, 1978). If there is more than one process in the field (as in the neuropil), larger processes, and/or we use signal averaging, then this sensitivity is greatly increased. For example, the axon in Figure 4 had a diameter of $25 \mu \mathrm{m}$ and was stimulated $100 \times$ with a train of 17 action potentials. In this case, we would estimate that we could see changes in the commissure corresponding to an increase of about $50 \mathrm{nM}$ calcium per impulse if the axon were filled with $0.25 \mathrm{~mm}$ dye.

After each experiment the stimulated cell was iontophoretically filled with Lucifer yellow. The cell was then photographed using epifluorescence (50 W mercury lamp, BG3 and BG12 prefilters, and 0G510 post- filter; Schott) as previously described (Ross and Krauthamer, 1984) This photograph was used to correlate positions on the cell with elements of the photodiode array. The ganglion was then fixed in buffered formalin (pH 7.4), dehydrated, cleared in methyl salicylate, and rephotographed.

In order to assign a signal detected on a particular photodiode element to a location on the cell, it was important to know how well the cell was imaged on the array. Both the three-dimensionality of the neuronal geometry and scattering of light by the tissue degrade the image from what might be expected from a two-dimensional sheet. To measure the consequences of these effects, we placed a $20 \mu \mathrm{m}$ diameter aperture on the stage and varied the depth of focus. We found that with the 0.75 NA lens and with a grid spacing of $40 \mu \mathrm{m}$ there was no significant spread of signal to adjacent diodes until we defocused over $100 \mu \mathrm{m}$. The effect of light scattering by the tissue was assayed by placing the aperture under the ganglion in saline. In this case, scattering spreads signals over 
about a $50-\mu \mathrm{m}$-diameter area. However, this estimate is worse than the real situation since the cell bodies are superficial with their processes within the ganglion, and only the tissue above the cell participates in the signal scattering. These conclusions are confirmed in the montage shown in Figure 3. In thin areas, such as the axon in the commissure or around the soma that bulges out of the ganglion, there is no signal outside the boundary. Similar analyses were made by Salzberg et al. (1977) and Orbach and Cohen (1983) using another apparatus with different lenses.

Arsenazo III changes its absorbance in response to changes in $\mathrm{pH}$ and to changes in $\mathrm{Mg}$ ion concentration. Also, there is some controversy (Ahmed et al., 1980; Brown and Rydqvist, 1981; Palade and Vergara, 1983; Rios and Schneider, 1981; Thomas, 1979) about the stoichiometry and kinetics of the calcium-dye reaction. Therefore, we have made several control experiments and used reasonable assumptions in establishing that the changes in absorbance we measure indicate changes in calcium ion concentration of the correct magnitude and time course.

Two experiments showed that the absorbance changes were the result of changes in $[\mathrm{Ca}]_{\mathrm{i}}$ resulting from calcium flow through voltage-dependent calcium channels. First, the signals were greatly reduced when the $20 \mathrm{~mm}$ external calcium was replaced with $2 \mathrm{mM} \mathrm{Ca}$ and $18 \mathrm{~mm}$ Co or if $1 \mathrm{~mm} \mathrm{Cd}$ was added to the saline. In other preparations (Hagiwara and Byerly, 1981), these procedures block calcium currents through calcium channels. In addition, the absorbance increased during the time the cell was depolarized and began to decline at the end of the stimulation. Therefore, it is unlikely that we were detecting calcium-stimulated calcium release from internal stores, since this process would peak later as a result of the diffusion time of calcium in the cytoplasm. Second, the action spectrum at each position in the cell (Fig. $2 A$ ) resembled that expected from changes in [Ca $]_{i}$ and not that expected from changes in $[\mathrm{Mg}]_{\text {i }}$ or $\mathrm{pH}$ (Ahmed and Connor, 1979; Baylor et al., 1982b; Gorman and Thomas, 1980). We found, as did these previous workers, that the peak at $660 \mathrm{~nm}$ was larger than the peak at $610 \mathrm{~nm}$, the opposite of that found with Ca-Arsenazo III in a cuvette. This difference may be due to the fact that calcium and Arsenazo III can form more than one complex (Palade and Vergara, 1983; Rios and Schneider, 1981) and the distribution of complexes in the cell may vary from those found at equilibrium in the cuvette. This spectral difference, however, is not the result of the dye responding to ions other than calcium because the action spectrum for $\mathrm{pH}$ and $\mathrm{Mg}$ changes is quite different.

We also found that there was a small, but consistent, time-course variation with wavelength. Signals recorded at $600 \mathrm{~nm}$ recovered faster than those recorded at $620-660 \mathrm{~nm}$ (Fig. 2B). Ahmed and Connor (1979) reported similar results and attributed the variation to a late $\mathrm{pH}$ change, possibly due to calcium sequestration coupled to proton release at the mitochondria. Palade and Vergara (1982) also found differences between signals at various wavelengths. However, Rakowski and Jost (1984), using a rapid scanning spectrometer, found that the action spectrum in muscle fibers is essentially the same at all times after a stimulus, and they defend the use of Arsenazo III as an indicator of the time course of calcium transients. Another complication is that both Palade and Vergara (1982) and Baylor et al. (1983) found small differences in the time courses for rapid calcium transients in muscle using Arsenazo III and another indicator dye, Antipyralazo III. These observations require that we interpret the time-course measurements cautiously. Nevertheless, we believe that the time-course measurements give useful information because (1) we used (in most experiments) relatively short stimulating trains, which are not expected to cause a significant $\mathrm{pH}$ signal (Zucker, 1981); (2) the time constants we measured were typically more than $10 \times$ slower than those recorded in muscle fibers (Baylor et al., $1982 \mathrm{~b}$ ) and hence the reactions were closer to equilibrium and less complicated by the transitions among the Ca-Arsenazo III species; and (3) we generally drew conclusions from the differences in time course in different parts of the cell and not from the value of the time constant itself.

\section{Results}

\section{Distribution of signals}

In a typical experiment, Arsenazo III was injected into the soma of a CC cell and the dye was allowed to diffuse throughout the cell. The soma was then repetitively stimulated using the same electrode. In order to improve the signal-to-noise ratio, a train of 5-20 action potentials was typically used and records were signal-averaged $10-100 \times$. Figure 3 shows the absorbance changes at $640 \pm 30 \mathrm{~nm}$ detected by each element of the array when a hundred $500 \mathrm{msec}$ depolarizing pulses were delivered to the cell, eliciting a burst of 17 action potentials per sweep. In this cell the experiment was repeated with two overlapping fields in order to cover the entire cell. The shaded area represents the neuron as determined by imaging scaled photographs of the Lucifer yellow fill (Fig. 4) over the montage (see Materials and Methods). In all positions over the cell, there is a sharp increase in absorbance during the time of stimulation; the absorbance then declined to baseline. There were no signals in positions outside the cell boundary. Some small movement artifacts occurred near the edge of the ganglion.

Since calcium diffuses slowly in cytoplasm $\left(D=3 \times 10^{-1}\right.$ $\mathrm{cm}^{2} \mathrm{sec}^{-1}$; Blaustein and Hodgkin, 1969) and the time to peak was about the same in all positions, the location of absorbance changes must correspond closely to the sites of calcium entry, the calcium channels. In this cell the wide distribution of absorbance changes showed that there were calcium channels on the soma, axon, and dendritic processes. There were no locations on this cell without channels.

The CC cell described above was capable of supporting calcium-dependent action potentials in TTX. Another cell, the MG cell, was not excitable in TTX, even when $50 \mathrm{~mm}$ TEA was added to the saline to block outward current. In this cell we could also detect stimulated changes in absorbance in all parts of the cell. However, it was our impression that the absorbance changes in the axon were much smaller than those detected in the $\mathrm{CC}$ cell under the same conditions for axons of about the same diameter and cells filled with about the same concentration of dye. This implies that the density of calcium channels was lower in the axon of the MG cell than in the axons of the CC cell. We could not make this comparison quantitative because of our inability to measure the concentration of Arsenazo III in the axons. However, the qualitative difference between the two cells is consistent with their different excitability in TTX. Calcium channels have previously been demonstrated in the squid giant axon, which is also unexcitable in TTX (Baker et al., 1971; Brown et al., 1975; Dipolo et al., 1983) and in the axon of the barnacle photoreceptor (Edgington and Stuart, 1979).

\section{Variations in calcium channel density}

Using either direct iontophoretic injection of calcium into muscle fibers (Miledi et al., 1980) and into the presynaptic terminal of the squid giant synapse (Miledi and Parker, 1981) or stimulated entry into Aplysia neurons (Gorman and Thomas, 1980), it has been shown that the absorbance change is proportional to the change in internal calcium in the physiological range. Consequently, if the duration of the stimulus is short compared to the time for calcium removal, the amplitude of the absorbance change recorded by each photodiode should be proportional to the change in the amount of calcium in the cell in the area subtended by that diode element as long as the concentration of dye in the cell is uniform. If we assume that the properties of calcium channels are the same on all parts of the cell and that the potential change during the stimulus was the same at all places on the cell, then the signals are proportional to the number of calcium channels under each element. To translate these numbers into channel density requires accurate measurement of the surface area in each region. For neurons with complicated geometries, this kind of analysis is not always possible. However, we have been able to examine special regions of some cells with this method.

Figure 5 shows the absorbance change at six positions along the axon in the commissure of the $\mathrm{CC}$ cell. Here, the axon was of uniform diameter with no side branches. The figure shows that the signal size was constant along the commissure, implying a relatively uniform density of calcium channels. 


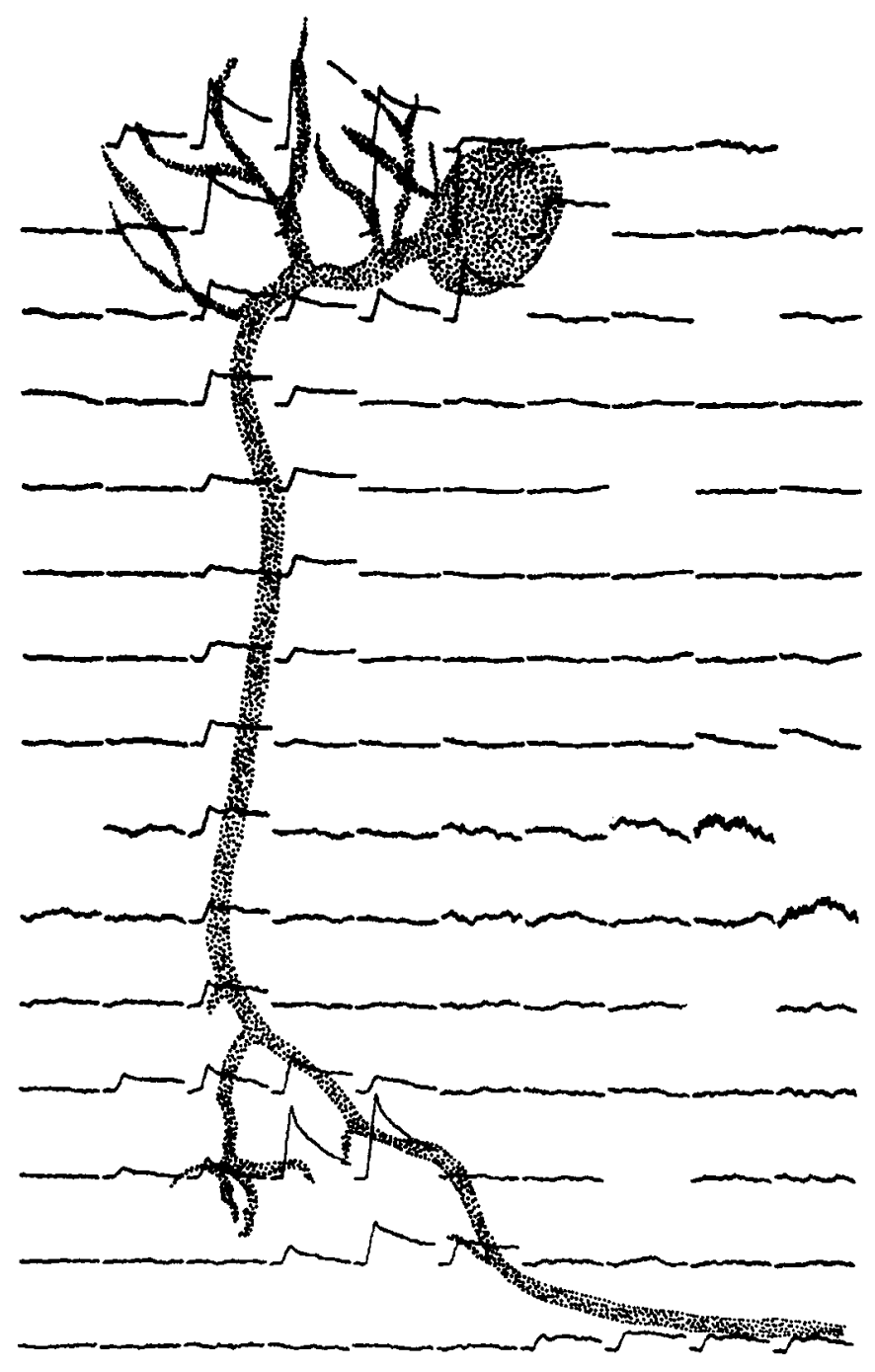

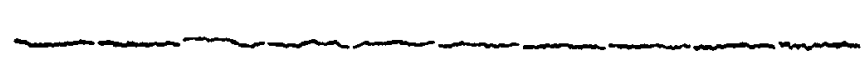

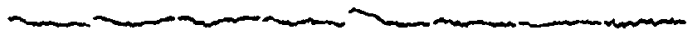

Figure 3. Time course of absorbance changes measured simultaneously at many positions over a CC cell. Significant signals were seen at all positions on the cell. The scale factor for the amplitudes is the same at all positions. Several locations in the somatic region were off-scale and have been cut off. The area covered by each pixel is a square $\left(64 \mu \mathrm{m}^{2}\right)$ whose bottom edge is along the bottom of the absorbance signal from that element. Two photodiode elements were not working and are shown as blanks. Since the entire cell could not fit in the microscopic field, the experiment was repeated at two positions and the amplitudes matched at overlapping pixels. The cell was stimulated with a train of action potentials in normal saline during the rising phase of each trace. The duration of each trace is $5 \mathrm{sec} ; 100$ sweeps were averaged. The outline of the cell was determined from the Lucifer yellow-filled cell shown in Fig. 4. Only the major processes are shown in the ipsilateral neuropil.

The arborization of the $\mathrm{CC}$ cell in the contralateral hemiganglion could be reconstructed from serial photographs of wholemounts, and the surface area in each region could be estimated. This region was far enough away from the point of dye injection (the soma) that it is likely that the dye concentration was fairly uniform. (Further confirmation of this point comes from the fact that the time course of the signal was similar in the commissure and in the axon. Since the time course is sensitive to the concentration of dye, this suggests that the concentration was uniform - see "Time course of calcium transients," below, for further discussion.) Figure 6 shows the results from a typical cell. We divided the cell in the contralateral ganglion into three regions, two axonal segments and one region containing the neuropil. In each region the sum of the signals from all the pixels was divided by the calculated surface area (see figure legend). The figure shows that the normalized signal in the neuropil region was about $3 \times$ as large as in the axonal regions, implying that calcium channels are distributed more densely in neuropil regions than along axons. If the Arsenazo III did not penetrate well into the neuropil, then the true ratio would be even larger. Similarly, if the action potentials causing the signals failed to propagate into the processes, the ratio would also be larger. The more complex neuropil of this cell in the ipsilateral hemiganglion precluded a detailed analysis in that region. However, the data for the ipsilateral region (Fig. 7) are also consistent with a high neuropil density of calcium channels.

\section{Spread of excitability}

The wide distribution of Arsenazo III absorbance signals over the surface of these cells suggested the possibility that they could be used to indicate the spread of potential within the cell. Since both calcium channels and membrane depolarization are necessary to cause calcium influx, and calcium channels are present everywhere in these cells, then the location of the absorbance changes indicates the places where the membrane potential was depolarized enough to open the channels.

One application of this approach is to determine whether and where somatically stimulated potentials propagate. In normal saline, the MG cell action potential is almost entirely sodiumdependent. Yet there appear to be calcium channels at low density all along the axon as absorbance signals are found when the cell is stimulated to fire action potentials (Fig. 8). When TTX is added to the saline and the soma depolarized, the absorbance changes are confined to the somatic region. This restricted distribution of signals is due to the declining amplitude of the electrotonically spreading depolarization. Within a short distance from the soma (150-200 $\mu \mathrm{m})$, the amplitude of the pulse is not large enough to open sufficient calcium channels to produce an absorbance signal. The exact value of potential where this transition occurs is not known in this cell. However, based on voltage-clamp measurements of currents and Arsenazo III absorbance changes in other species (Ahmed and Connor, 1979; Gorman and Thomas, 1980; Smith and Zucker, 1980), significant calcium signals would not be seen if the potential was below $-20 \mathrm{mV}$. Passively spreading potentials are attenuated below this level because of the voltage-dependent potassium conductances in the membrane; hence, the short space constant for the absorbance signal.

When the same kind of experiment is done on the CC cell, which has been demonstrated to have a propagating calciumdependent action potential in the presence of TTX (Lewenstein, 1983; Lewenstein and Ross, 1984a), there is little difference in the absorbance signal distribution with or without TTX (Fig. 9). Similarly, the figure shows that the ratio of signals with or without TTX remains close to 1.0 along the axon of the MC cell after normalizing the ratio to 1.0 in the soma. This demonstrates that the calcium spike in this cell also propagates.

We can also use these results to argue that action potentials propagate into the processes of the $\mathrm{CC}$ cell. Figure 7 shows that, in this cell, strong signals are found out to the tips of the dendrites, often more than $200 \mu \mathrm{m}$ away from the axon, with no indication of a reduction in signal amplitude with distance faster than the reduction in density of neuropil processes at the edge of the arbor. This suggests that the signal per unit membrane 


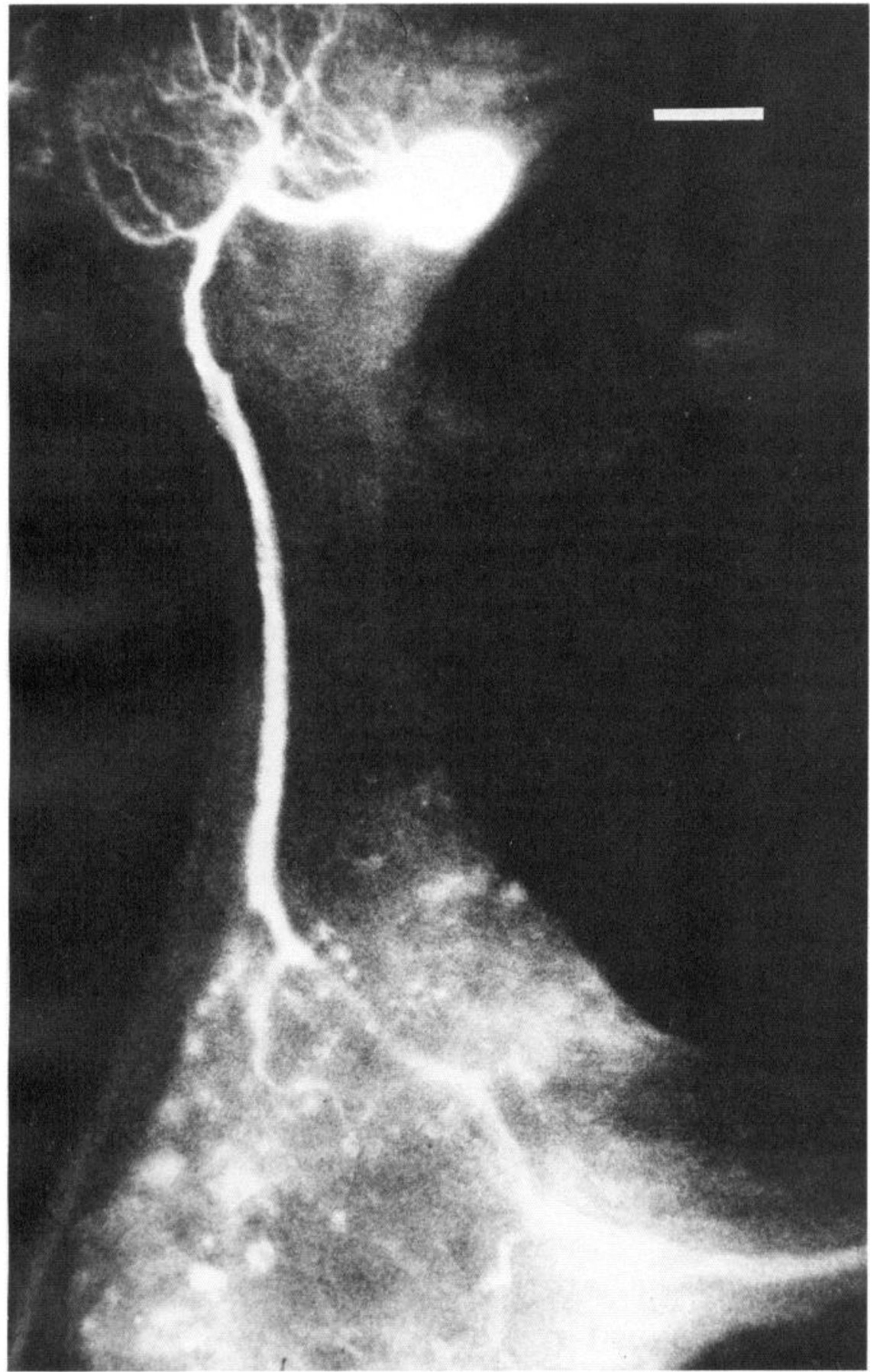

Figure 4. Fluorescence photograph of the $\mathrm{CC}$ cell used in the experiment illustrated in Figure 3. The cell has been iontophoretically filled with $\mathrm{Lu}-$ cifer yellow. The background autofluorescence outlines the boundaries of the supraesophageal ganglion. The pictures were taken with a $10 \times, 0.22$ NA lens to increase the depth of field. Under the $25 \times$ lens used in the experiment, less of the cell was in focus. Bar, $64 \mu \mathrm{m}$.

area is not declining rapidly in the dendrites. When propagation clearly fails, as in the TTX-treated MG cell, no signals are seen $200 \mu \mathrm{m}$ along the axon. Since the space constant of the dendrites is likely to be shorter than that of the axon because of their smaller diameters, we would expect the signals to drop even faster in this region if propagation failed.

This argument is consistent with the fact that the density of calcium channels is higher in the processes than in the axon, where propagation is clearly supported, even in TTX. In fact, Figure 10 shows that propagation into the dendrites also persists in TTX, since the ratio of signals in TTX to that in normal saline is at least 1.0 at all positions in the dendritic arbor. Hence, the calcium channels in the dendrites are dense enough by themselves to support active propagation.
It is interesting that the ratio of signals in TTX to that in normal saline is close to 1.0 along the axon but is significantly higher in the dendritic region. One possibility is that TTX affects the action potential differently in the dendrites than in the other regions. In the soma (Lewenstein and Ross, 1984a), TTX reduces the peak spike amplitude by about $30 \%$ and increases the duration of the spike by about $160 \%$. If these changes are different in the dendritic region because of different proportions of sodium and calcium channels, the different ratios would be explained.

\section{Time course of calcium transients}

Since the reaction time of Arsenazo III is fast, i.e., within milliseconds (Baylor et al., 1982b; Brown et al., 1975), the time 
Figure 5. Amplitude of the absorbance change measured at six positions along the commissure of a CC cell. Since the axon was of uniform diameter in this region, the absorbance changes are proportional to the density of calcium channels showing uniform density in this region. The amplitude was determined by measuring the absorbance change between the beginning and end of the stimulus. For the first three points, the commissure passed between two diode elements and their amplitudes were added to give the total absorbance change. No correction was made for the dead space between diode elements (about $7 \%$ ). Error bars indicate the peakto-peak noise for each pixel during a time interval before the cell was stimulated.

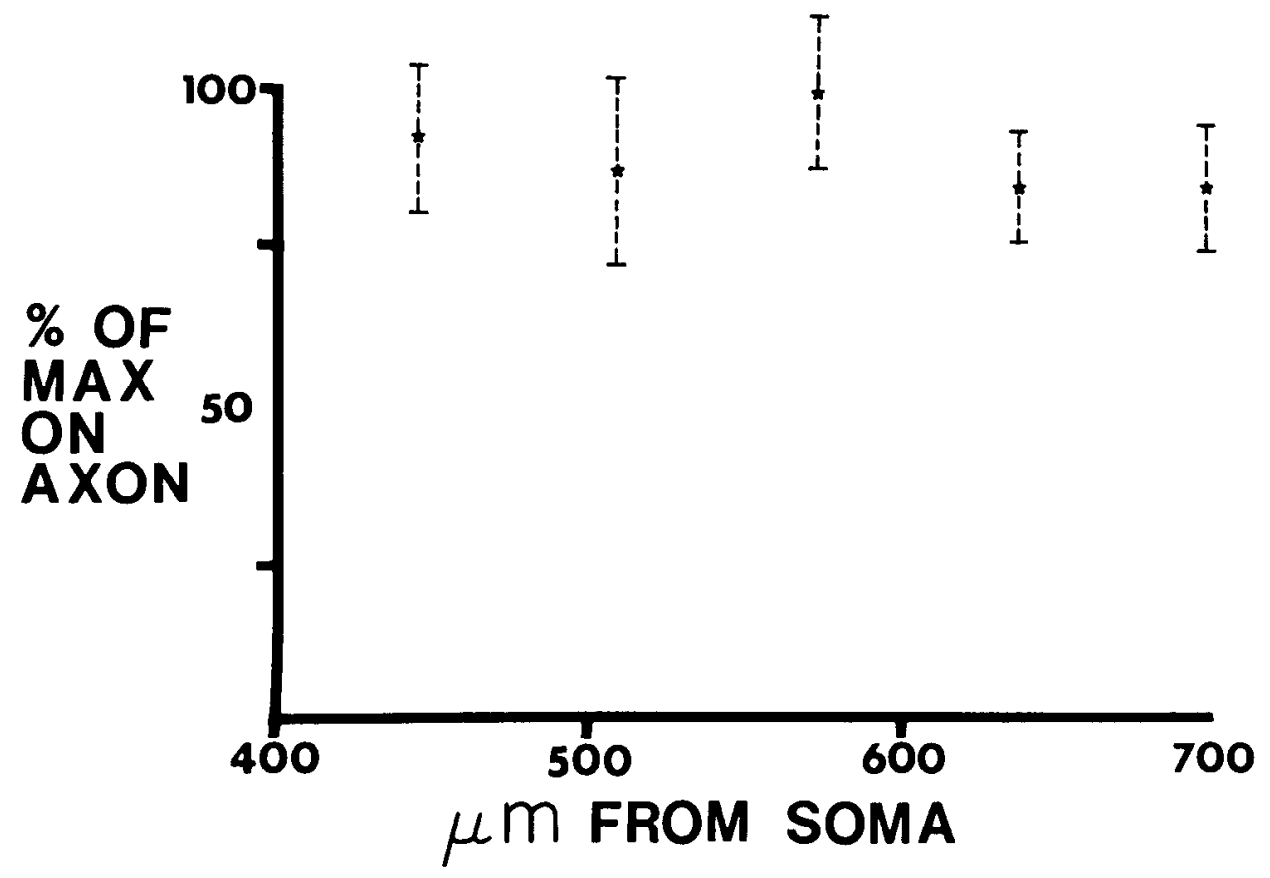

course of the absorbance change is expected to be close to the time course of the change in intracellular free calcium (see Materials and Methods for discussion of this point). However, the dye is itself a calcium buffer, so it can slow the normal time course. Gorman and Thomas (1978), in their work on cell R15 in Aplysia, found that the time course was unaffected at dye concentrations below about $0.4 \mathrm{~mm}$ because the natural cytoplasmic buffers were powerful enough to dominate the recovery process. Similar results were found by Baylor et al. (1982b) for muscle sarcoplasm. However, in one cell we found that concentrations of Arsenazo III above $0.25 \mathrm{~mm}$ seemed to have some effect on the removal time course. In a typical experiment, in-

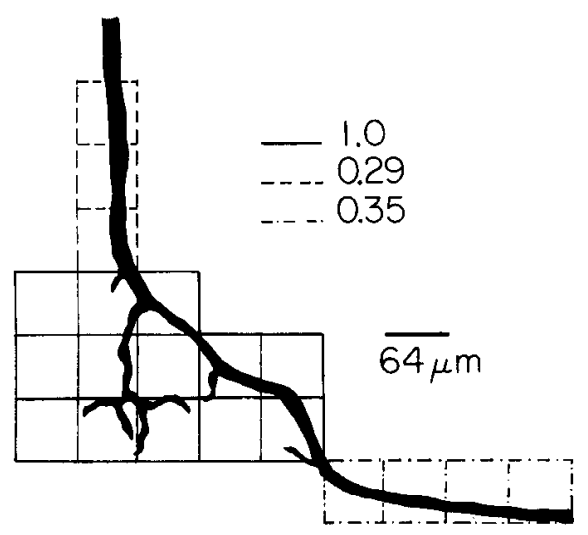

Figure 6. Relative number of calcium channels in the contralateral neuropil of the $\mathrm{CC}$ cell compared with two axonal regions on either side. In each region, the total absorbance change was determined by adding the amplitudes of each pixcl. The surface area was determined by first reconstructing the cell from a through-focus series (every $10 \mu \mathrm{m}$ ) of the Lucifer yellow-filled neuron. The cell was then divided into a series of cylindrical segments, and the maximum diameter and length of each segment was determined. The relative signal sizes in the three regions were $0.21 / 1.0 / 0.17$; the relative areas, $0.72 / 1.0 / 0.49$. All ratios have been normalized to 1.0 in the neuropil region. The lower signalto-area ratio in the axonal regions indicates a lower calcium channel density. If parts of the cell were out of focus or if the segments were not of uniform diameter, we would overestimate the area in the neuropil, indicating an actually greater ratio between the regions. creasing the concentration in the soma from 0.3 to $1.5 \mathrm{~mm}$ gradually increased the average time constant from 2.0 to 6.1 sec. (The time course was not a simple exponential, but we have used the time to decline to 0.37 of the peak amplitude as a measure of the fall time.) In addition, the center of the cell had a slower time constant than the edge and was more affected by higher concentrations of dye. These effects are illustrated in Figure 11. At $0.27 \mathrm{~mm}$ dye, the average time constant for the 10 pixels over the edges of this cell was $1.2 \mathrm{sec}$ and the average time constant for the 2 central pixels was $2.27 \mathrm{sec}$. However, when the concentration was increased to $1.1 \mathrm{~mm}$, the two time constants were 8.1 and $29 \mathrm{sec}$. This great increase is consistent with the increased buffering power of Arsenazo III. In fact, the buffering power of Arsenazo III is proportional to the square of the dye concentration (Gorman and Thomas, 1978). To compensate for these effects we tried to use the lowest dye concen-

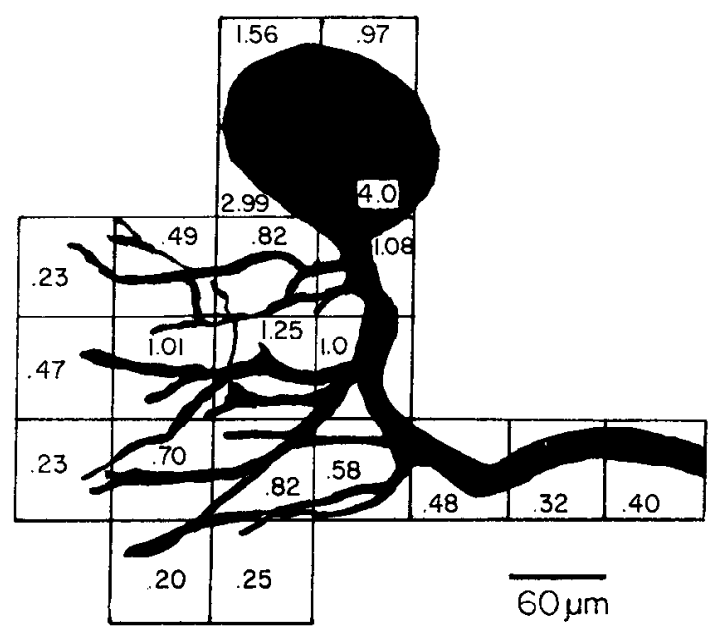

Figure 7. There are significant absorbance signals on all elements covering the ipsilateral neuropil when the $\mathrm{CC}$ cell is intrasomatically stimulated with a train of action potentials. The amplitude of the absorbance changes has been normalized to a value of 1.0 over a position on the axon near the branch points of most of the neuropil processes. The numbers have not been normalized to the surface area in each pixel. 


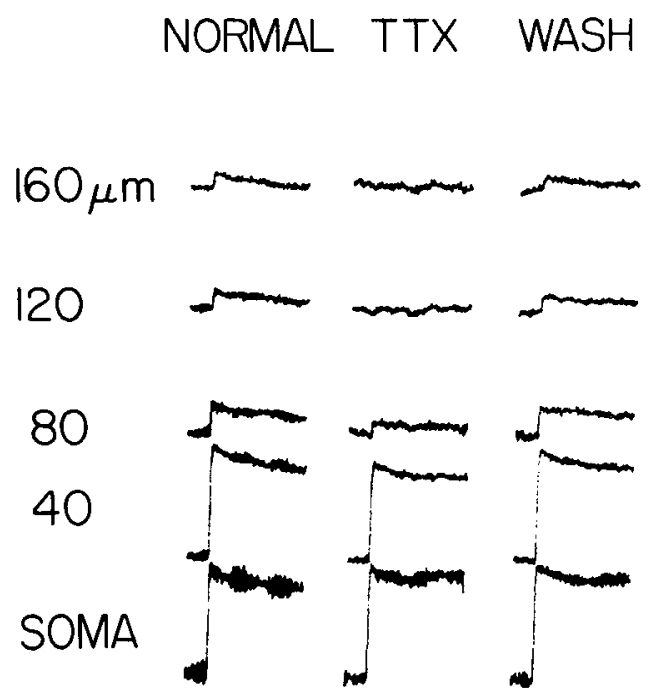

Figure 8. Absorbance signals are eliminated along an axon of an MG cell in TTX when the neuron is intrasomatically stimulated. Each column shows the relative absorbance change at five positions along the axon, normalized to a constant amplitude in the soma. In normal saline, the 25 -msec-wide stimulating pulse elicited a pair of action potentials that were detected on the antennular nerve. In TTX, these action potentials were eliminated and the absorbance signals no longer detected $160 \mu \mathrm{m}$ from the soma. After a wash in normal saline, both the action potentials and the absorbance signals returned. Each trace is $2.5 \mathrm{sec}$ long and is the average of 50 sweeps. The ratio of the TTX signals to the normal signals at each position is shown in Figure 9 (triangles).

tration that would give usable signals and to wait a long time (usually more than $1 \mathrm{hr}$ ) for the dye to distribute itself uniformly.

One consistent result was that the time course for removal was faster in the processes than in the soma or axon. An example of this is shown in Figure 12. In this experiment, the stimulus protocol was two bursts of action potentials lasting for $1 \mathrm{sec}$, separated by $2.2 \mathrm{sec}$. Over positions in the dendritic field the time constant of decay was much faster than in the soma. However, along the axon the time course remained about as slow as in the soma. The figure also shows that the time courses were essentially unchanged after waiting an additional $2 \mathrm{hr}$. This implies that the dye distribution was close to equilibrium within a half-hour after filling the cell. Therefore, the differences in

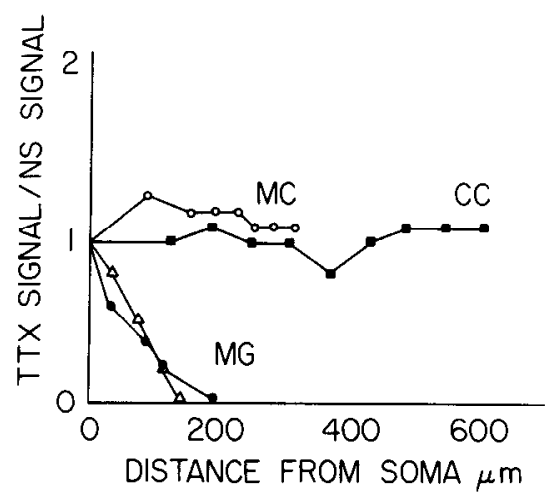

Figure 9. Ratio of absorbance signals in saline containing TTX to the signals at the same positions in normal saline for points along the axons of four cells-CC, MC, and two MGs. The ratios have been normalized to 1.0 at the point of stimulation in the soma. The ratios stay close to 1.0 in the CC and MC cells, but drop rapidly to zero in the MG cell, showing that propagation persists in TTX in the first two cells but not in the MG cell.

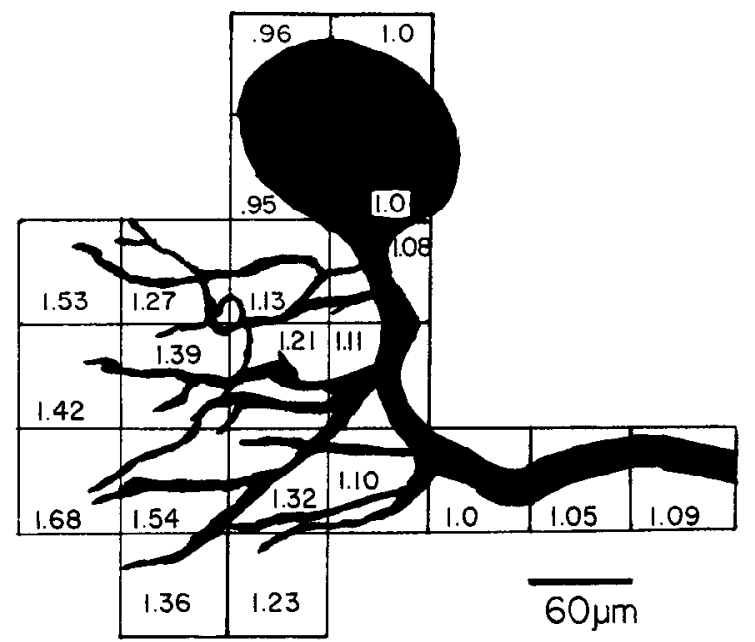

Figure 10. Ratio of absorbance signals in saline containing TTX to the signal in normal saline for positions over the $\mathrm{CC}$ cell. The ratios have been normalized to 1.0 in the soma. As in Figure 9, the ratios are close to 1.0 along the axon. In addition, the ratio is 1.0 or greater in the neuropil, showing propagation into this region in TTX.

time course are not likely to result from differences in dye concentration in the different regions.

Figure 12 also illustrates one of the consequences of the different time courses. In the soma and axon, the calcium transient from the first burst did not return to baseline when the second burst began. Consequently, the second transient summed with the remainder of the first one. In the processes the first transient was over when the second began and there was no additive effect with this stimulus interval.

Another example is from the neuropil region of the $\mathrm{CC}$ in the contralateral hemiganglion. In this case the arborization is far from the soma and is bracketed by the axon in the commissurc and the axon going out the contralateral antennular nerve. Figure 13 shows the recovery time course for four positions over the arborization and positions over the axon both before and after the neuropil. The time course is clearly faster in the neuropil region. The fact that the same slow time course was seen
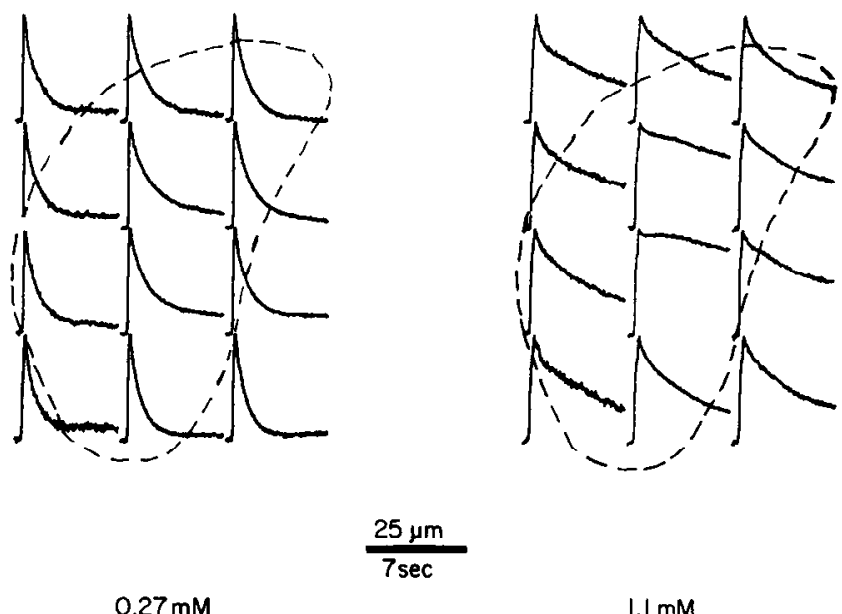

I. $1 \mathrm{mM}$

Figure 11. Comparison of the time course of recovery of the absorbance signal at the center and edges of the soma of a CC cell at two dye concentrations. The recovery times are faster at the edges of the cell and at lower concentrations. All signals have been normalized to the same amplitude. The dotted line shows the outline of the cell body determined from the boundary of the pink Arsenazo III in the cell. Dye concentration was determined as described in the text. 

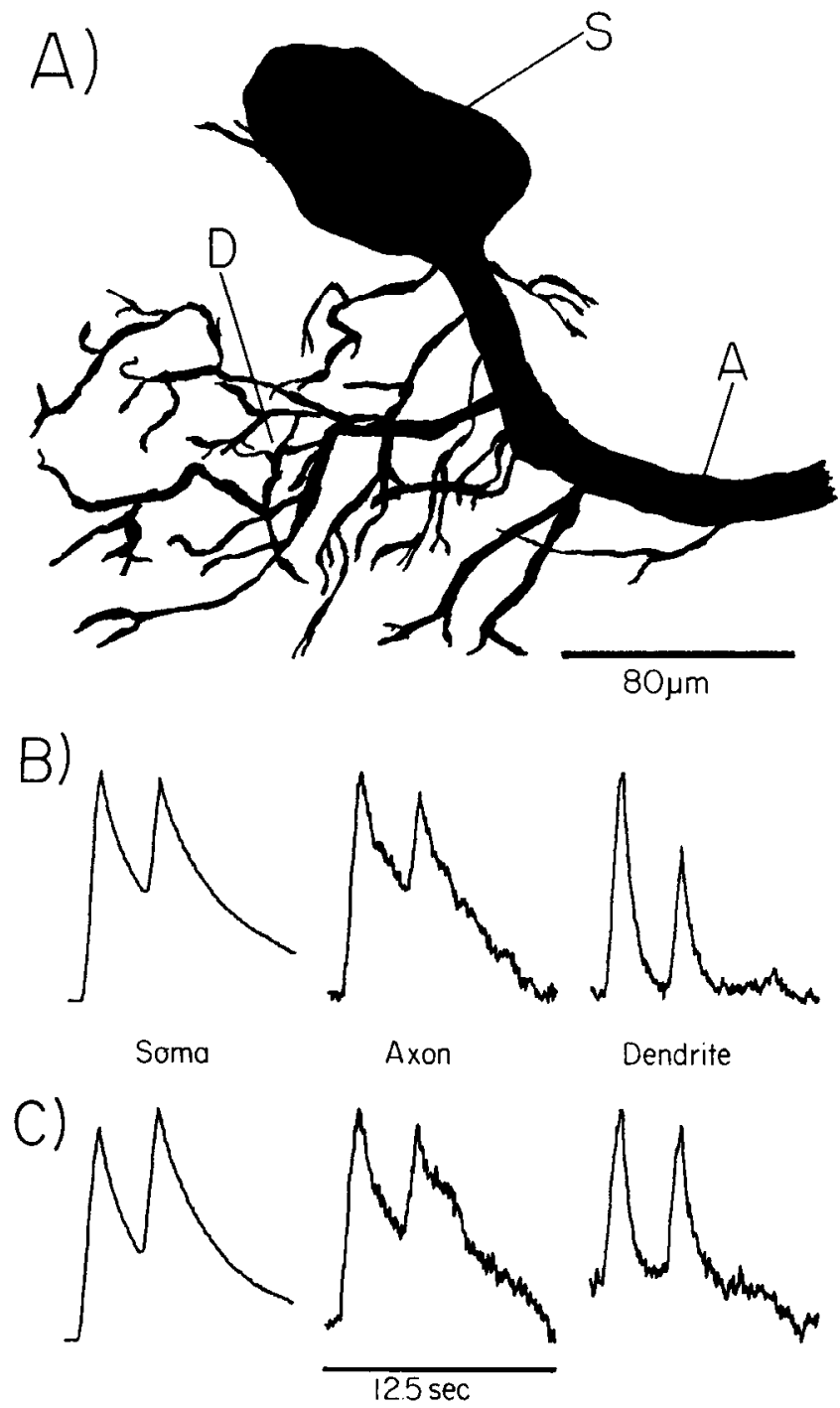

Figure 12. Time course of the absorbance transient is faster in the neuropil than in the axon or soma. $A$, Outline of the $C C$ cell determined from a Lucifer yellow injection after the experiment. $B$, Absorbance transients recorded in the soma, axon, and dendritic regions of the cell when it was stimulated with two trains of action potentials separated by $2.2 \mathrm{sec}$. Measurements were made about $20 \mathrm{~min}$ after the injection of dye into the soma. $C$, Same measurements repeated after waiting another $2 \mathrm{hr}$. Diffusion of the dye during this time has not significantly affected the time course in any region. Signals have all been normalized to the same amplitude. Twenty sweeps were averaged in each experiment.

on both sides of the arborization assures that the dye concentration was probably the same throughout the field, since the diffusion rate should be independent of the size of the process. Fast time courses were also seen over the neuropil of other cells, e.g., the MC cell.

The second significant difference in time course over different regions occurs when calcium enters over a long period, either as the result of a train of action potentials in normal saline or from a long-lasting action potential when TEA is added to the saline to block voltage-dependent potassium conductances. For single action potentials or short bursts, there was almost a linear increase in absorbance with time at all positions, reflecting a steady entry of calcium all over the cell (see, for example, Figs. 3 and 13). However, with the wide action potential or trains of normal action potentials, the absorbance changes over the processes leveled off and sometimes declined after several hundred

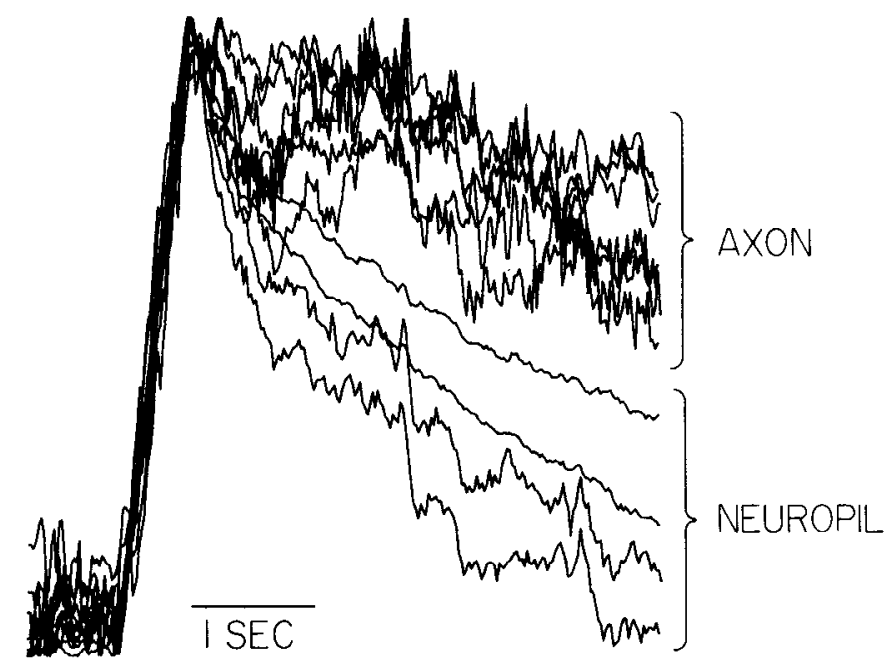

Figure 13. Comparison of time course of calcium transients in 12 positions over the $\mathrm{CC}$ cell in the contralateral hemiganglion. The four fastest recovery times were recorded from positions over the neuropil. Four of the other traces were from the axon in the commissure and the last four from the axon in the antennular nerve. This is the same cell as in Figure 3, which shows these signals in less detail. Signals have been normalized to the same amplitude.

milliseconds while continuing to rise over the somatic and axonal regions (Fig. 14). This plateau was most distinct in pixels containing the ends of the processes. Sometimes there was a smooth transition from plateau signals at the tips to nonplateau signals over the axon and soma. In other cases, there was a sharper transition, with plateau signals appearing over all positions away from the main axon.

These plateau signals were not due to the dye saturation by calcium, for two reasons. First, they were seen at several dye concentrations. If the effect were due to dye saturation, we would expect increases in dye concentration to result in less evidence of a plateau. Second, the signals began to decline immediately after the stimulus was turned off. If the dye were saturated it would take some time before the calcium level was reduced enough to see a decline in absorbance. The possibility that the plateau is due to the failure of propagation of some action potentials can also be ruled out since the time when the signal begins to decline is about the same in all regions of the cell. Therefore, the different time courses are likely to reflect real differences among the soma, axon, and dendritic regions. Possible explanations for this plateau effect are discussed below.

\section{Discussion}

The ability to make simultaneous records of calcium transients from all parts of a neuron, including small processes, should be a useful method for exploring questions involving the regional specialization of neurons, e.g., synaptic integration, propagation of potentials within cells, and the reponse of neurons to transmitters and pharmacological agents that are mediated in some way by calcium. In this paper we have examined a few of these possibilities.

When neurons in the supraesophageal ganglion were excited with depolarizing pulses in their somata, Arsenazo III absorbance changes were detected all over the cell. Controls established that they were caused by calcium entry from the external medium. Therefore, the calcium must have entered through voltage-dependent calcium channels, directly demonstrating their presence in all parts of the cell. Many of these channels may be related to release sites for synaptic transmitter. Several investigators have found synaptic contracts along most of the processes within the neuropil in other invertebrate preparations (King, 

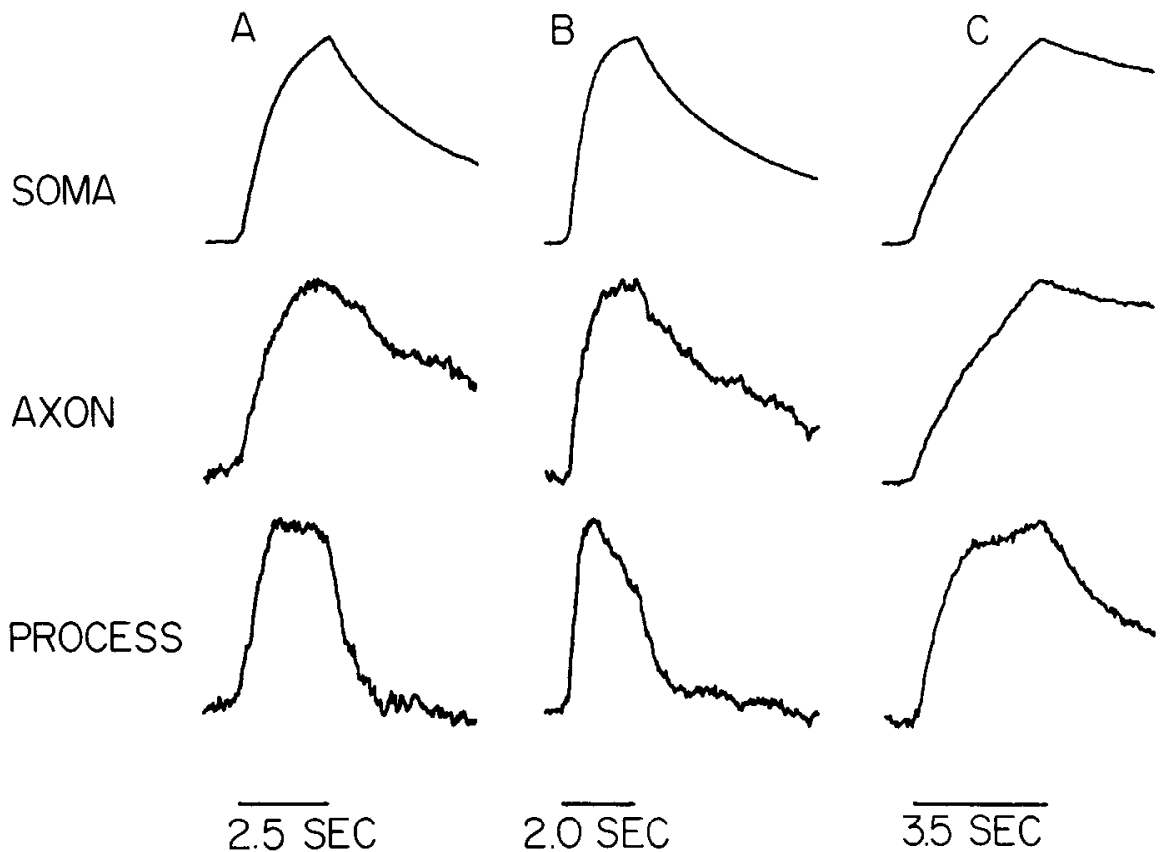

$2 \longdiv { O S E C }$

3.5 SEC

Figure 14. Comparison of the rising phase of the absorbance signals in the soma, axon, and neuropil of the CC cell. For long trains or wide action potentials, the absorbance signals reach a plateau $(A, C)$ and sometimes decline $(B)$ in the neuropil, while continuing to rise in the soma and axon. $A$, Cell stimulated with a train of action potentials for $2.5 \mathrm{sec} ; 25$ sweeps were averaged. $B$, Another cell stimulated for $2.0 \mathrm{sec}$; 20 sweeps were averaged. $C$, A third cell in $50 \mathrm{~mm}$ TEA. A $500 \mathrm{msec}$ pulse elicited an action potential that lasted $3.5 \mathrm{sec}$; no averaging.
1976; Muller and McMahan, 1976; Purves and McMahan, 1972). However, we have also found calcium channels in the somata and axons of several cells. In these cases, the calcium channels are unlikely to be related to release mechanisms and may serve other functions.

We have attempted, in several cases, to measure the relative density of calcium channels in different regions of neurons. This requires accurate measurement of the surface area of the neuron under each photodiode element. Unfortunately, the complicated geometry of most neurons makes these measurements difficult. In the photoreceptor presynaptic terminal (Stockbridge and Ross, 1984), the ratio of signal sizes in the terminal to that in the axon was so large that the determination of higher channel density in the terminal could be made with confidence. Along the commissure of the CC cell the axon was unbranched and of constant diameter, so the conclusion that there is uniform channel density is also likcly to be true. This result is of some interest, since, on the basis of electrophysiological experiments on cell R2 of Aplysia, Horn and Miller (1977) suggested that the density in that axon was not uniform but declined along the axon away from the soma.

We also determined that the density of calcium channels was higher in the contralateral neuropil of the CC cell than along the axon. In making this determination, we were conservative in our measurements of the surface area of the visible processes. However, it is possible that not all processes were filled with Lucifer yellow. For example, Taghert et al. (1982), using an antibody to Lucifer yellow, found fine filopodia in growing grasshopper axons that had not been visible with the dye alone. Although we cannot rule out the existence of nonvisualized processes, the area of this network would have to be three times the one visualized to negate our conclusion.

In this discussion of channel density, we are assuming that the properties of calcium channels are the same in all parts of the cell, since the experiments only determine the absorbance change per unit area. Recently, it has been discovered (e.g., Armstrong and Matteson, 1985; Llinás and Yarom, 1981) that there may be at least two different kinds of calcium channels in some neuronal membranes. If this is also true for barnacle neurons, then our experiments cannot be easily interpreted in terms of channel density.
Because calcium channels are found all over these barnacle neurons, we were able to use the presence of absorbance signals in different regions as a marker for the extent of potential spread in these cells. This method is particularly useful for following action potentials because the threshold for significant calcium entry is about $-20 \mathrm{mV}$, and passive potentials will decline below this voltage within a short distance in most cells. Using this technique we could demonstrate that calcium spikes propagate along the axon and into the neuropil of some cells, even in the presence of TTX. Calcium spikes have been observed in the dendrites of some vertebrate neurons (e.g., Llinás and Sugimori, 1980), but thcy have not bccn reported in the processes of invertebrate cells. Using voltage-sensitive dyes, Krauthamer and Ross (1984) were able to determine that the dendrites of some barnacle neurons were excitable. But the ionic composition of the dendritic spike was not determined.

The time course of both the rise and fall of the calcium transient was found to vary in different parts of the cell. One consistent finding was that the recovery time was faster at the edges of the soma than at the center (see also Smith, 1980). This result is consistent with a simple model of calcium control within neurons (Smith, 1980; Zucker and Stockbridge, 1983), in which the main cause of the recovery is the pumping out of calcium through the plasma membrane and cytoplasmic buffering is by fixed, nonsaturable elements. However, there is little evidence to support the argument that the return to baseline level of the fast calcium transient is due to a membrane pump. Sodiumcalcium exchange is unlikely to be a significant factor, since we found no change in the time course of the absorbance signal when sodium was completely replaced by choline in the saline. Similar observations were also made by Tillotson and Gorman (1980) and R. S. Zucker and J. A. Connor (personal communication). In the squid axon, where this process has been studied most extensively, the role of this exchange is also small, comprising at most $20 \%$ of calcium removal (Baker and McNaughton, 1978). The importance of the uncoupled calcium pump (DiPolo and Beauge, 1983) has not been extensively investigated. In contrast, Baker and Schlaepfer (1978) have shown that calcium is rapidly buffered when directly injected into isolated squid axoplasm, demonstrating that membrane pumps are not necessary for fast recovery of transients. 
Two other mechanisms are likely to play an important role in determining the time course of the calcium transient: a highaffinity, low-capacity, non-ATP-dependent cytoplasmic buffer (Baker and Schlaepfer, 1978) and a nonmitochondrial, ATPdependent sequestration mechanism (Blaustein et al., 1978). If these are the dominant processes, then their kinetics must be nonlinear in order to explain the faster time course we measure at the edge of the cell. Another possibility is that these mechanisms are more concentrated near the periphery of the cell than near the center (Tillotson and Gorman, 1980). Connor and Nikolakopoulou (1982) have incorporated these cytoplasmic mechanisms into a computer model of calcium transients and have succeeded in reproducing the time course of calcium removal. At present the relative importance of pumps or buffers is not clear for our cells. However, in a study of the role of internal calcium in controlling the kinetics of the calcium-activated potassium conductance in molluscan neurones, Barish and Thompson (1983) suggested that calcium buffering was the dominant mechanism in that system.

The faster kinetics of calcium removal measured in the neuropil compared to those in the soma or axon could be due to either a greater density of pumps and/or sequestration mechanisms or the greater surface-to-volume ratio in the neuropil. In either case, it is interesting that in the neuropil, where synaptic interactions take place, calcium levels are under the strongest regulation.

The saturating rising phase of the calcium signal detected on the processes for long stimuli is another significant difference betwecn this region and the soma and axon. As explained above, it cannot be due to saturation of the dye or failure of propagation into the neuropil. One possibility is that the saturation is a result of a greater inactivation of calcium channels (Eckert and Tillotson, 1981) or activation of a greater calcium-dependent potassium conductance (Meech, 1978) on the dendrites than on the soma or axon. Either could happen if the calcium entering the dendrites did not diffuse away from the surface because of the small diameter of the processes. In this case, the concentration of calcium would rise to a higher level in the processes than in those parts of the cell with larger volumes. Another contributing element is the faster removal time course observed in the processes. If this reflects an easily activated removal mechanism, then an equilibrium between the influx and efflux of calcium would be attained at early times, resulting in the plateau. So far, we have no information on the relative importance of these three mechanisms.

The saturation of calcium influx in the processes is not likely to affect the propagation of single action potentials in the cell. However, this mechanism may be significant when a neuron fires a train of action potentials. A particular example of some interest is the cerebellar Purkinje cell, which is known to have dendritic calcium channels and to fire bursts of action potentials (Llinás and Sugimori, 1980).

\section{References}

Ahmed, Z., and J. A. Connor (1979) Measurement of calcium influx under voltage clamp in molluscan neurones using the metallochromic dye Arsenazo III. J. Physiol. (Lond.) 286: 61-82.

Ahmed, Z., L. Kragie, and J. A. Connor (1980) Stoichiometry and apparent dissociation constant of the calcium-Arsenazo III reaction under physiological conditions. Biophys. J. 32: 907-920.

Armstrong, C. M., and D. R. Matteson (1985) Two distinct populations of calcium channels in a clonal line of pituitary cells. Science 227: 65-67.

Baker, P. F., and P. A. McNaughton (1978) The influence of extracellular calcium binding on the efflux from squid axons. J. Physiol. (Lond.) 276: 127-150.

Baker, P. F., and W. W. Schlaepfer (1978) Uptake and binding of calcium by axoplasm isolated from giant axons of Loligo and Myxicola. J. Physiol. (Lond.) 276: 103-125.
Baker, P. F., A. L. Hodgkin, and E. B. Ridgway (1971) Depolarization and $\mathrm{Ca}$ entry in squid giant axons. J. Physiol. (Lond.) 218: 709-755.

Barish, M. E., and S. H. Thompson (1983) Calcium buffering and slow recovery kinetics of calcium-dependent outward current in molluscan neurones. J. Physiol. (Lond.) 337: 201-219.

Baylor, S. M., W. K. Chandler, and M. W. Marshall (1982a) Optical mcasurcments of intracellular $\mathrm{pH}$ and magnesium in frog skeletal muscle fibers. J. Physiol. (Lond.) 331: 105-137.

Baylor, S. M., W. K. Chandler, and M. W. Marshall (1982b) Use of metallochromic dyes to measure changes in myoplasmic calcium during activity in frog skeletal muscle fibers. J. Physiol. (Lond.) 331:139 177.

Baylor, S. M., M. E. Quinta-Ferreira, and C. S. Hui (1983) Comparison of isotropic calcium signals from intact frog muscle fibers injected with Arsenazo III or Antipyrylazo III. Biophys. J. 44: 107-112.

Blaustein, M. P., and A. L. Hodgkin (1969) The effect of cyanide on the efflux of calcium from squid axons. J. Physiol. (Lond.) 200:497527.

Blaustein, M. P., R. W. Ratzlaff, N. C. Kendrick, and E. S. Schweitzer (1978) Calcium buffering in presynaptic nerve terminals. I. Evidence for involvement of a non-mitochondrial ATP-dependent sequestration mechanism. J. Gen. Physiol. 72: 15-41.

Blinks, J. R., W. G. Wier, P. Hess, and F. G. Prendergast (1982) Measurement of $\mathrm{Ca}^{21}$ concentrations in living cells. Prog. Biophys. Mol. Biol. 40: 1-114.

Brown, H. M., and B. Rydquist (1981) Arsenazo III-Ca ${ }^{2+}$. Effect of $\mathrm{pH}$, ionic strength, and Arsenazo III concentration on equilibrium binding evaluated with $\mathrm{Ca}^{2+}$ ion-sensitive electrodes and absorbance measurements. Biophys. J. 36: 117-137.

Brown, J. E., L. B. Cohen, P. deWeer, L. H. Pinto, W. N. Ross, and B. M. Salzberg (1975) Rapid changes of intracellular free calcium concentration: Detection by metallochromic indicator dyes in squid axon. Biophys. J. 15: 1155-1160.

Brown, J. E., P. K. Brown, and L. H. Pinto (1977) Detection of lightinduced changes of intracellular ionized calcium concentration in Limulus ventral photoreceptors using Arsenazo III. J. Physiol. (Lond.) 267: 299-320.

Charlton, M. P., S. J. Smith, and R. Zucker (1982) Role of presynaptic calcium ions and channels in synaptic facilitation and depression at the squid giant synapse. J. Physiol. (Lond.) 323: 173-193.

Connor, J. A., and G. Nikolakopoulou (1982) Calcium diffusion and buffering in nerve cytoplasm. Lectures Math. Life Sci. 15: 79-101.

DiPolo, R., and L. Beauge (1983) The calcium pump and sodiumcalcium exchange in squid axons. Annu. Rev. Physiol. 45: 313-324.

DiPolo, R., J. Requena, F. J. Brinley, Jr., L. J. Mullins, A. Scarpa, and T. Tiffert (1976) Ionized calcium concentrations in squid axons. J. Gen. Physiol. 67: 433-467.

DiPolo, R., C. Caputo, and F. Bezanilla (1983) Electrical recording of a voltage-dependent $\mathrm{Ca}$ conductance in the squid axon. Proc. Natl. Acad. Sci. USA 80: 1743-1745.

Eckert, R., and D. L. Tillotson (1981) Calcium mediated inactivation of the calcium conductance in caesium-loaded giant neurones of $A p l y$ sia californica. J. Physiol. (Lond.) 314: 265-280.

Edgington, D. R., and A. E. Stuart (1979) Calcium channels in the high resistivity axonal membrane of photoreceptors of the giant barnacle. J. Physiol. (Lond.) 294: 433-445.

Gilkey, J. C., L. F. Jaffe, E. B. Ridgway, and G. T. Reynolds (1978) A free calcium wave traverses the activating egg of the medaka, Oryzias latipes. J. Cell. Biol. 76: 448-466.

Gorman, A. L. F., and M. V. Thomas (1978) Changes in the intracellular concentration of free calcium ions in a pacemaker neurone, measured with the metallochromic indicator dye Arsenazo III. J. Physiol. (Lond.) 275: 357-376.

Gorman, A. L. F., and M. V. Thomas (1980) Intracellular calcium accumulation during depolarization in a molluscan neurone. J. Physiol. (Lond.) 308: 259-285.

Grinvald, A., L. B. Cohen, S. Lesher, and M. B. Boyle (1981a) Simultaneous optical monitoring of activity of many neurons in invertebrate ganglia using a 124-element photodiode array. J. Neurophysiol. 45: 829-840.

Grinvald, A., W. N. Ross, and I. Farber (1981b) Simultaneous optical measurements of electrical activity from multiple sites on processes of cultured neurons. Proc. Natl. Acad. Sci. USA 78: 3245-3249.

Grinvald, A., R. Hildesheim, I. C. Farber, and L. Anglister (1982) Improved fluorescent probes for measurement of rapid changes in potential. Biophys. J. 39: 301-308. 
Hagiwara, S. (1973) Ca spike. Adv. Biophys. 4: 71-102.

Hagiwara, S., and L. Byerly (1981) Calcium channel. Annu. Rev. Neurosci. 4: 69-125.

Harary, H. H., and J. E. Brown (1984) Spatially nonuniform changes in intracellular calcium ion concentrations. Science 224: 292-294.

Horn, R., and J. J. Miller (1977) A prolonged voltage-dependent calcium permeability revealed by TEA in the soma and axon of Aplysia giant neuron. J. Neurobiol. 8: 399-415.

Hudspeth, A. J., and A. E. Stuart (1977) Morphology and response to light of the somata, axons, and terminal regions of individual photoreceptors of the giant barnacle. J. Physiol. (Lond.) 272: 1-23.

Katz, B. (1969) The Release of Neurotransmitter Substances. The Sherrington Lectures, Charles C Thomas, Springfield, IL.

Katz, B., and R. Miledi (1969) Tetrodotoxin-resistant electrical activity in presynaptic terminals. J. Physiol. (Lond.) 203: 459-487.

King, D. G. (1976) Organization of crustacean neuropil. II. Distribution of synaptic contacts on identified motor neurons in lobster stomatogastric ganglion. J. Neurocytol. 5: 239-266.

Krauthamer, V., and W. N. Ross (1984) Regional variations in excitability of barnacle neurons. J. Neurosci. 4: 673-682.

Lewenstein, L. A. (1983) Propagating calcium spikes in identified cells in the supraesophageal ganglion of the giant barnacle. Biol. Bull. 165: 529.

Lewenstein, L. A., and W. N. Ross (1984a) Tetrodotoxin resistant propagating calcium spikes in identified neurons of the giant barnacle, Balanus nubilus. Soc. Neurosci. Abstr. 10: 868.

Lewenstein, L. A., and W. N. Ross (1984b) Regional properties of calcium entry in a barnacle neuron. Biol. Bull. 167: 529.

Lewenstein, L. A., N. Stockbridge, and W. N. Ross (1984) Regional calcium entry in neurons of the giant barnacle. Biophys. J. 45:180a.

Llinás, R., and M. Sugimori (1979) Calcium conductances in Purkinje cell dendrites: Their role in development and integration. Prog. Brain Res. 51: 323-334.

Llinás, R., and M. Sugimori (1980) Electrophysiological properties of in vitro Purkinje cell dendrites in mammalian cerebellar slices. $J$. Physiol. (Lond.) 305: 197-213.

Llinás, R., and Y. Yarom (1981) Properties and distribution of ionic conductances generating electroresponsiveness of mammalian inferior olivary neurones in vitro. J. Physiol. (Lond.) 315: 569-584.

Llinás, R., M. Sugimori, and J. M. Bower (1983) Visualization of depolarization-evoked presynaptic calcium entry and voltage dependence of transmitter release at the squid giant synapse. Biol. Bull. 165: 529.

Meech, R. W. (1978) Calcium-dependent potassium activation in nervous tissue. Annu. Rev. Biophys. Bioeng. 7: 1-18.

Miledi, R., and I. Parker (1981) Calcium transients recorded with Arsenazo III in the presynaptic terminal of the squid giant synapse. Proc. R. Soc. Lond. [Biol.] 212: 197-211.

Miledi, R., I. Parker, and G. Schalow (1980) Transmitter induccd calcium entry across the post-synaptic membrane at frog endplates measured using Arsenazo III. J. Physiol. (Lond.) 300: 197-212.

Muller, K. J., and U. J. McMahan (1976) The shapes of sensory and motor neurones and the distribution of their synapses in ganglia of the leech. Proc. R. Soc. Lond. [Biol.] 194: 481-499.

Mullins, L. J., and J. Requena (1979) Calcium measurement in the periphery of an axon. J. Gen. Physiol. 74: 393-413.

Nakajima, S., A. Gilai, and D. Dingeman (1976) Dye absorption changes in single muscle fibers: An application of an automatic balancing circuit. Pfluegers Arch. 362: 285-287.
Orbach, H., and L. B. Cohen (1983) Optical monitoring of activity from many areas of in vitro and in vivo Salamander olfactory bulb: A new method for studying functional organization in the vertebrate central nervous system. J. Neurosci. 3: 2251-2262.

Palade, P., and J. Vergara (1982) Arsenazo III and Antipyralazo III calcium transients in single skeletal muscle fibers. J. Gen. Physiol. 79: 679-707.

Palade, P., and J. Vergara (1983) Stoichiometry of Arsenazo III-calcium complexes. Biophys. J. 43: 355-369.

Purves, D., and U. J. McMahan (1972) The distribution of synapses on a physiologically identified motor neuron in the central nervous system of the leech. J. Cell. Biol. 55: 205-220.

Rakowski, R. F., and M. C. Jost (1984) Difference spectra recorded from voltage clamped frog skeletal muscle fibers injected with Ar III. J. Gen. Physiol. 84: 13a-14a.

Rasmussen, H. (1981) Calcium and cAMP as Synarchic Messengers, Wiley, New York.

Rios, E., and M. F. Schneider (1981) Stoichiometry of the reactions of calcium with the metallochromic indicator dyes Antipyrylazo III and Arsenazo III. Biophys. J. 36: 607-621.

Ross, W. N., and V. Krauthamer (1984) Optical measurements of potential changes in axons and processes of neurons of a barnacle ganglion. J. Neurosci. 4: 659-672.

Ross, W. N., L. A. Lewenstein, and N. Stockbridge (1984) Regional calcium entry in neurons of the giant barnacle detected with Arsenazo III. Soc. Neurosci. Abstr. 10: 1075.

Salzberg, B. M., A. Grinvald, L. B. Cohen, H. V. Davila, and W. N. Ross (1977) Optical recording of neuronal activity from an invertebrate ganglion: Simultaneous detection from several cells. J. Neurophysiol. 40: 1281-1291.

Smith, S. J. (1980) $\mathrm{Ca}^{++}$regulation in gastropod nerve cell bodies. In Molluscan Nerve Cells: From Biophysics to Behavior, J. Koester and J. H. Byrne, eds., pp. 81-91, Cold Spring Harbor Laboratory, New York.

Smith, S. J., and R. S. Zucker (1980) Aequorin response, facilitation and intracellular calcium accumulation in molluscan neurones. $\mathbf{J}$. Physiol. (Lond.) 300: 167-196.

Stockbridge, N., and W. N. Ross (1984) Localized $\mathrm{Ca}^{2+}$ and calciumactivated potassium conductances in terminals of a barnacle photoreceptor. Nature 309: 266-268.

Taghert, P. H., M. J. Bastiani, R. K. Ho, and C. S. Goodman (1982) Guidance of pioneer growth cones: Filopodial contacts and coupling revealed with an antibody to Lucifer Yellow. Dev. Biol. 94: 391-399.

Thomas, M. V. (1979) Arsenazo III forms 2:1 complexes with $\mathrm{Ca}$ and 1:1 complexes with $\mathrm{Mg}$ under physiological conditions. Biophys. J. 25: 541-548.

Thomas, M. V., and A. L. F. Gorman (1977) Internal calcium changes in bursting pacemaker neuron measured with Arsenazo III. Science 196: 531-533.

Tillotson, D., and A. L. F. Gorman (1980) Non-uniform Ca buffer distribution in a nerve cell body. Nature 286:816-817.

Zucker, R. S. (1981) Cytoplasmic alkalization reduces calcium buffering in molluscan central neurons. Brain Res. 225: 155-170.

Zucker, R. S., and N. Stockbridge (1983) Presynaptic calcium diffusion and the time course of transmitter release and synaptic facilitation at the squid giant synapse. J. Neurosci. 3: 1263-1269. 